\title{
Trust in a Vial
}

It is impossible to go through life without trust: that is to be imprisoned in the worst cell of all, oneself.

Graham Greene, Ministry of Fear

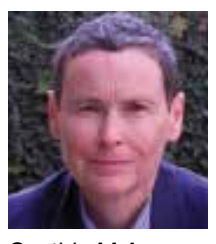

Cynthia M.A.

Geppert, MD,

Editor-in-Chief

Correspondence:

Cynthia Geppert

(ethicdoc@comcast.net)

Fed Pract. 2021;38(1):4-5. doi:10.12788/fp.0084
0 n December 11, 2020, the US Food and Drug Administration (FDA) delivered the holiday gift America was waiting for-approval of the first COVID-19 vaccine. Following the recommendation of its expert advisory panel, the FDA issued its opening emergency use authorization (EUA) for the Pfizer and BioNTech product to be distributed and administered across the country. ${ }^{1} \mathrm{~A}$ week after that historic announcement, the FDA issued an EUA to Moderna for a second COVID-19 vaccine. ${ }^{2}$

An EUA is a misunderstood concept that, like the development of the vaccine itself, appears almost like a magical federal deliverance to a nation at a time when almost every other public health effort has floundered. An EUA is a regulatory process to enable a public health emergency response with medical countermeasures including not only vaccines, but also medications. Earlier in 2020, hydroxychloroquine and remdesivir each received EUAs for treating patients with COVID-19. ${ }^{3}$ The EUA for hydroxychloroquine was later revoked when more data raised concerns for its efficacy. ${ }^{4}$ EUAs do not mean the drugs are experimental or that everyone receiving them is participating in a research trial; however, for the sake of safety and science, data continue to be collected and analyzed. Issuance of an EUA indicates that after rigorous examination and an independent advisory board review of data submitted by the manufacturer, the FDA has determined the product and situation meet key criteria: (1) There is a public health emergency that threatens health and life and requires expedited procedures; (2) there are no extant approved products able to treat or prevent the disease; and (3) the known and potential benefits of the product outweigh the known and potential risks. ${ }^{5}$

The public and even the professional press have celebrated the arrival of this technologic triumph over a virus that had vanquished staggering numbers of lives and livelihoods. Much of the media coverage aptly chose the word "hope" to capture the significance of this unprecedented accomplishment for which so many millions yearned. A Google search for "hope" on the morning of December 20, yielded 339,000,000 results. For example, a headline especially salient for Federal Practitioner readers from the New York Times read, "A Shot of Hope' What the Vaccine is like for Frontline Doctors and Nurses." 6

I want to briefly argue why even though I believe hope in and for the vaccine is desperately needed if we are to survive this long, dark winter, trust in the vaccine can actually usher in the warmth of economic recovery and the light of saved lives. Trust is crucial in 3 main areas if the awe-inspiring hope of the vaccine the EUAs codify is to be fulfilled. The venerable moral and civic virtue of trust has been trivialized and commercialized mostly mentioned in advertising for insurance or real estate companies. Medical virtue-ethicists Edmund Pellegrino and David Thomasma describe trust as the binding force that keeps civilization intact. "Trust is ineradicable in human relationships. Without we could not live in society or attain even the rudiments of a fulfilling life, they explain. "Without trust we could not anticipate the future, and we would therefore be paralyzed into inaction. Yet to trust and entrust is to become vulnerable and dependent on the good will and motivations of those we trust. Trust, ineradicable as it is, is also always problematic."

The first area where that trust is the hardest to secure is in the federal government, the actions and messages of which have seemed so inconstant, unjust, and deceptive to many. For enough citizens to roll up their sleeves, they must believe the outgoing and the incoming administrations and legislators can make rational plans translated into sound public health policy that place the good of humanity above other interests and then mobilize the resources of the country to deliver that good with consistency, fairness, and transparency.

The second area is trust in medical science. 
Long before COVID-19, American attitudes toward vaccines reflected reasonable fears and ridiculous conspiracy theories-both of which are serious obstacles to the breadth of immunization required to achieve herd immunity. Ordinary people must believe that the health care professionals and scientists at the Centers for Disease Control and Prevention and the FDA will never compromise safety for political expediency. Recent polls have shown an increase in the percentage of the population willing to consider vaccination. A December Gallop poll found that $63 \%$ of Americans were willing to be vaccinated for COVID-19. ${ }^{8}$ To raise those numbers high enough to approach herd immunity will require Americans to believe that the scientists who discover the vaccines and the companies that develop them have placed people above profit and ranked the safety of society above individual scientific renown.

Groups that have been the historic objects of exploitation in research and contemporary disparities in health care understandably have more distrust of science and medicine. While public health officials insist that they have developed a system of vaccine distribution that is equitable and prioritizes the sick and old and those who care for them before the rich and powerful, we should not be surprised that our communication of this assurance is viewed with skepticism. As a recent Medscape article advised, public health officials may need to rely on, "trusted messengers" to help some communities to "overcome vaccine hesitancy."

Third we must trust in our fellow citizens to maintain the public health measures of social distancing and mask wearing even after there is widespread vaccination. If we are to reap the benefits of a safe and effective vaccine, we must be a community of immunity, not just isolated inoculated individuals. We as health care practitioners must do all we can to educate the public that the adverse reactions to the vaccine so prominently featured in the media are expected with any new and complex biological product and do not signal risk that outweighs the deadliness of the virus. ${ }^{10}$

Fourth, and finally, we must trust in ourselves as health care professionals and administrators. We in the DoD, VA, and PHS have the knowledge and skills to endure the onslaught of pain and suffering we will all experience in one way or another in these next long months. We must believe that our courage and compassion can turn a vaccine into vaccinations sufficient to relieve the COVID-19 siege of our hospitals and intensive care units. When that day comes, hope will have been a plan we could trust.

\section{Disclaimer}

The opinions expressed herein are those of the author and does not necessarily reflect those of Federal Practitioner, Frontline Medical Communications Inc., the US Government, or any of its agencies.

\section{References}

1. US Food and Drug Administration. FDA take key action in fight against COVID-19 by issuing emergency use authorization for first COVID-19 vaccine [press release]. Published December 11, 2020. Accessed December 22, 2020. https:// www.fda.gov/news-events/press-announcements/fda-takes -key-action-fight-against-covid-19-issuing-emergency-use -authorization-first-covid-19

2. US Food and Drug Administration. FDA takes additional action in fight against COVID-19 by Issuing emergency use authorization for second COVID-19 vaccine [press release]. Published December 18, 2020. Accessed December 22, 2020. https://www.fda.gov/news-events/press-announce ments/fda-takes-additional-action-fight-against-covid-19 -issuing-emergency-use-authorization-second-covid

3. US Food and Drug Administration. FDA approves first treatment for COVID-19 [press release]. Published October 22, 2020. Accessed December 20, 2020. https://www.fda.gov /news-events/press-announcements/fda-approves-first-treat ment-covid-19

4. US Food and Drug Administration. Coronavirus (COVID-19) update: FDA revokes emergency use authorization for chloroquine and hydroxychloroquine [press release]. Published June 15, 2020. Accessed December 22, 2020. https://www .fda.gov/news-events/press-announcements/coronavirus -covid-19-update-fda-revokes-emergency-use-authorization -chloroquine-and

5. US Food and Drug Administration. Emergency use authorization for vaccines explained. Updated November 20 , 2020. Accessed December 22, 2020. https://www.fda.gov /vaccines-blood-biologics/vaccines/emergency-use-authori zation-vaccines-explained

6. Healy J, Tompkins L, Burch ADS. 'A shot of hope': what the vaccine is like for frontline doctors and nurses. New York Times. Updated December 17, 2020. Accessed December 22, 2020. https://www.nytimes.com/2020/12/14/us/corona virus-vaccine-doctors-nurses.html

7. Pellegrino E, Thomasma DC. The Virtues in Medical Practice. New York: Oxford University Press; 1993:65.

8. Brenan M. Willingness to get Covid-19 vaccine ticks up to $63 \%$ in the U.S. Published December 8, 2020. Accessed December 22, 2020. https://news.gallup.com/poll/327425 /willingness-covid-vaccine-ticks.aspx

9. Eldred SM. Trusted messengers may help disenfranchised communities overcome vaccine hesitancy. Published December 17, 2020. Accessed December 22, 2020. https://www .medscape.com/viewarticle/942847

10. Chiu A. 'Absolutely normal': Covid vaccine side effects are not reason to avoid the shots, doctors say. Washington Post. Published December 3, 2020. Accessed December 22, 2020. https://www.washingtonpost.com/lifestyle/wellness/vaccine -side-effects-covid/2020/12/02/55bebac0-342c-11eb-8d38 -6aea1adb3839_story.html 